\title{
O PROCESSAMENTO METACOGNITIVO NO ATO DE LEITURA: REPENSANDO O ENSINO
}

\author{
Roza Maria Palomanes Ribeiro
}

\section{RESUMO}

A meta do presente artigo é apresentar discussão e propostas em torno do comportamento inconsciente e automático do leitor durante a atividade de ler (processamento cognitivo), bem como as atividades realizadas por ele, de maneira controlada (processamento metacognitivo). Através de atividades metacognitivas, o aluno estabelece conexóes entre os variados saberes alcançando compreensão do que lê.

PALAVRAS-CHAVE: processamento cognitivo; processamento metacognitivo; competência leitora.

\section{Introdução}

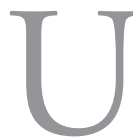

$\mathrm{m}$ dos maiores desafios dos professores de língua portuguesa do ensino fundamental é ensinar a ler com proficiência. Nas últimas décadas, investigaçóes acerca da aprendizagem centram seu foco nos aspectos cognitivos envolvidos em qualquer aprendizado, i.e., o comportamento inconsciente e automático do aluno face ao novo. Além dos processos cognitivos associados ao aprendizado, os processos metacognitivos que coordenam as aptidóes cognitivas envolvidas na memória, leitura e compreensão de textos têm sido levados em conta desde a década de 1970 por autores como Brown, 1978, Flavell \& Wellman, 1977 e Flavell, 1979, para citar alguns autores.

Ao se pensar no ensino de leitura, não há como excluir essas variáveis processos cognitivos e metacognitivos - na análise de todo o processo. Exaustivamente se tem estudado acerca da compreensão textual e sabe-se que todo 
conhecimento armazenado na memória é ativado, inconscientemente, para que se estabeleça sentido para o que se lê. Essa atividade inconsciente é parte do que chamamos processamento cognitivo, i.e., todo o comportamento inconsciente/automático do leitor ao ler um texto. Além desse comportamento inconsciente, o leitor, durante a atividade de leitura, realiza atividades conscientemente. Neste caso, passa por um processamento metacognitivo quando estabelece objetivos para a leitura, reflete sobre o que lê, formula hipóteses sobre o texto, procura nele elementos que possibilitem confirmá-las ou refutá-las e indaga sobre seu próprio entendimento do texto.

O presente artigo tem por objetivo promover reflexóes acerca dos processamentos cognitivos e metacognitivos do ato de ler a partir da análise de livros didáticos adotados por escolas do ensino fundamental do município do Rio de Janeiro. A partir da análise de três livros didáticos incluídos no PNLD (Programa Nacional do Livro Didático) de 2014, buscaremos observar como são apresentadas as atividades de leitura nesse material de apoio e se são adequadas, de acordo com as reflexóes teóricas aqui apresentadas, ao que se almeja alcançar nas aulas de leitura: a proficiência leitora.

As bases que sustentam esta pesquisa são teorias do campo das Ciências Cognitivas, especialmente os estudos na área da metacognição por se tratar de uma pesquisa que tem como premissa a ideia de que o alcance da leitura proficiente se pauta na consciência do indivíduo acerca do seu processo de aprendizagem. Como bem afirmam Flavell e Wellman (1977), citados por Ribeiro (2003, p. 109), a consciência metacognitiva é determinante no processo de aprendizagem:

[...] observou-se que os sujeitos eficientes na execução de tarefas acadêmicas possuíam também competências metacognitivas bem desenvolvidas, pois demonstraram compreender a finalidade da tarefa, planificar a sua realização, aplicar e alterar conscientemente estratégias.

A hipótese que norteia essa pesquisa de base qualitativa é a de que habilidades cognitivas e metacognitivas necessárias para que se alcance proficiência no ato de leitura, tais como, atenção, reflexão e inferenciação, por exemplo, não são suficientemente trabalhadas pelos professores que apoiam suas práti- 
cas em livros didáticos e materiais pedagógicos outros que promovem o contato com textos fragmentados, usando-os, muitas vezes, como pretexto para outras atividades que não a da leitura propriamente dita. Entende-se que sem atividades que permitam ao aluno o desenvolvimento de competências metacognitivas, a capacidade leitora fica prejudicada. A citação de Flavell (1979, p.906) é elucidativa a esse respeito:

[...] a metacognição possui um papel importante na comunicação oral, na persuasão, na compreensão oral, na compreensão leitora, na escrita, na aquisição da linguagem, na atenção, na memória, na solução de problemas, na cognição social e em várias formas de autocontrole e autoinstrução.

Nas seçóes seguintes serão apresentados, em detalhes, os pressupostos teóricos que sustentam esta pesquisa, materiais e métodos, além da análise de material didático como forma de sustentar a proposta apresentada.

\section{$O$ aprendizado da leitura}

Entre seis e sete anos de idade, a criança começa a ser alfabetizada. Os mecanismos que coordenam os processos de aquisição da língua oral e da língua escrita são considerados os mesmos, resguardando suas diferenças estruturais. A língua oral é aquela transmitida no lar e no convívio com os falantes que compóem a comunidade linguística na qual se insere a criança. Ao passo que a língua escrita é, em geral, oferecida ao indivíduo pela instituição escolar na modalidade da língua padrão.

Com relação aos estudos voltados para a alfabetização, vale ressaltar que, durante muito tempo, a prioridade era a preocupação com métodos e técnicas de alfabetização. Somente a partir da segunda metade do século XX, como afirma Palomanes (2012, p. 27), "graças às contribuiçóes da Linguística e outras ciências humanas dadas ao tema, a concepção de alfabetização recebeu novo status: a escrita passou a ser vista não como mero instrumento de aprendizagem escolar, mas como produto cultural”.

No entanto, apesar do grande interesse sobre alfabetização nas últimas décadas, observa-se que a prática escolar ainda se restringe ao ensino mecânico 
da escrita e da leitura, o que possibilita o analfabetismo funcional. Um grande número de docentes das escolas brasileiras, sobretudo os de ensino fundamental, ainda adota uma postura tradicional com relação à sua prática pedagógica, entendendo o aluno como um ser passivo. Acreditamos que, somente através de práticas consistentes de leitura e escrita, com textos que signifiquem algo ao aluno, permitindo que ele reflita e levante hipóteses sobre o que lê, com o professor desempenhando papel de intervir para tornar mais efetiva esta reflexão, é que se conseguem leitores eficientes.

$\mathrm{O}$ que ocorre na mente do leitor durante o ato de ler? O que permite ao leitor entender o texto lido? O processamento cognitivo da leitura envolve, dentre outras capacidades, a percepção do material linguístico na página impressa. Essa percepção acontece automaticamente quando se olha para as palavras dispostas na página, sem que se reflita conscientemente sobre esse processamento. A respeito da percepção de palavras no texto escrito, Mary Kato relata que:

As pesquisas em leitura, principalmente na área da psicologia e da psicolinguística, são unânimes em afirmar que, na leitura proficiente, as palavras são lidas náo letra por letra ou sílaba por sílaba, mas como um todo não analisado, isto é, por reconhecimento instantâneo e não por processamento analítico-sintético. (KATO, 2011, p. 33)

O processamento da leitura inconsciente é, pois, guiado pelo movimento dos olhos de tal forma que se reconhecem as palavras rapidamente. Kleiman (2010, p.37), afirma que "os olhos se fixam num lugar do texto (a fixação), para depois pular um trecho (a sacada), e fixar-se num outro ponto mais adiante". A esse movimento ocular dá-se o nome de sacádico.

Um leitor competente se faz, também, na capacidade e no uso das habilidades metacognitivas e metalinguísticas. Metacognitivas são as que consistem na habilidade de refletir sobre os próprios processos cognitivos e as metalinguísticas as que dizem respeito à manipulação deliberada e consciente dos objetos linguísticos. Para este artigo, serão considerados a capacidade e uso das habilidades metacognitivas.

Na próxima seção, serão apresentadas informações básicas sobre o processamento metacognitivo na leitura. 


\section{A metacognição e o ensino da leitura}

Estudos dentro das Ciências Cognitivas admitem que o fenômeno da cognição ocorre no processamento simbólico das relaçóes que os homens estabelecem consigo mesmos, com os outros e com o mundo, tendo relação ampla com a linguagem, uma vez que a capacidade cognitiva de pensar e transmitir ideias e sentimentos realiza-se por seu intermédio. Como ato ou processo de conhecer, a cognição envolve, portanto, habilidades como a atenção, a memória, o raciocínio, a imaginação e a linguagem.

Para que o indivíduo aprenda, é preciso que assimile, atue e opere sobre os objetos a sua volta, desconstruindo-os e construindo-os. O ser humano está imerso num meio em que a aprendizagem ocorre de forma constante. A todo o momento, deparamo-nos com situaçóes inteiramente novas ou situaçóes que já são conhecidas, mas que portam alguns elementos diferentes. Os homens, salvo casos específicos de distúrbios da mente, são capazes de utilizar as novas informaçóes adquiridas em diferentes contextos, evocando o que aprenderam, não somente na situação em que foram geradas e assimiladas, mas em diferentes contextos da vida.

A metacognição começou a ser estudada a partir de 1970 e vem ganhando força, sobretudo por pesquisadores voltados ao ensino de línguas. Flavell $(1979,1987)$ se destaca neste cenário como um dos pesquisadores mais atuantes e reconhecidos nesta área de estudos. Para Flavell (1987), a metacogniçâo é o processo pelo qual o indivíduo realiza operaçôes cognitivas, além de acompanhá-las enquanto acontecem. Trata-se, grosso modo, da consciência do falante acerca da própria cognição.

Flavell (1987) afirma ainda que, durante o processamento de informaçấo, o conhecimento metacognitivo, as experiências metacognitivas, os objetivos cognitivos e as açóes cognitivas entram em jogo. Por conhecimento metacognitivo entende-se o conhecimento que o indivíduo possui sobre suas características psicológicas e mentais, além do conhecimento que possui sobre a cognição do outro. Pode-se dizer que é um conhecimento de base; parte-se deste conhecimento para se alcançar os demais. Os conhecimentos que o indivíduo demonstra possuir nas variadas situaçôes, como o da compreensão leitora, por exemplo, são chamados por Flavell (op.cit) de experiências metacognitivas. Há, ainda, os objetivos cognitivos que dizem respeito à cons- 
ciência acerca das metas a serem alcançadas em situaçóes cognitivas, como, por exemplo, o que é esperado quando nos propóem a leitura de um texto. $\mathrm{E}$, finalmente, as estratégias conscientes de que o indivíduo lança mão para alcançar seus objetivos cognitivos, chamadas de açóes cognitivas. No caso da leitura, concentrar-se no que lê ou reler algum trecho em que tenha perdido a concentração são ações cognitivas de que o aluno lança mão para compreender o que lê.

Flavell (1987) apresenta três variáveis que afetam, diretamente, o conhecimento metacognitivo:

a) A variável pessoa: corresponde ao conhecimento que o indivíduo tem acerca da cognição universalmente, da cognição dos outros e da sua própria cognição;

b) A variável tarefa: relacionada ao conhecimento das pessoas sobre como lidar com as informaçôes; e

c) A variável estratégia: se refere ao conhecimento que se tem acerca dos resultados de uma estratégia e da eficácia dos seus resultados.

Para melhor entendimento de como atuam esses conhecimentos durante a atividade leitora, tomemos, como ilustração, uma prática docente comum: o professor pede que o aluno leia um texto em voz alta. Durante a leitura oral, o aluno tem consciência de que precisa fazer uma leitura com atenção, especialmente para as palavras que desconheça e para as informações novas veiculadas pelo texto. Todo esse comportamento e consciência estão relacionados ao conhecimento metacognitivo. No decorrer da leitura, o aluno começa a perceber se está ou não compreendendo o que lê, se a leitura está fácil, se as palavras novas podem ser inferidas. Essa é a experiência metacognitiva. De acordo com a proposta do professor - se deverá responder a questóes de interpretação ou se deverá escrever um resumo do que leu - o aluno começa a direcionar a leitura para alcançar esses objetivos. São os objetivos cognitivos. Os objetivos cognitivos vêm acompanhados, via de regra, por ações cognitivas. Se é preciso resumir o que leu, começa-se a sublinhar o que se considera mais relevante no texto. Se é preciso responder a algumas questões, começa-se a buscar pelas respostas no texto lido. 
Kleiman (2010, p. 54) define as estratégias metacognitivas como operações controladas conscientemente. Para Kato (2007, p. 132) são as estratégias metacognitivas que demonstram ser interessantes para a aprendizagem formal na escola em função de sua natureza consciente.

Para Flavell (1987), enquanto as estratégias cognitivas são destinadas pura e simplesmente a levar o sujeito a alcançar um objetivo cognitivo, as estratégias metacognitivas o permitem avaliar a eficácia das estratégias cognitivas. Voltando o foco à leitura, quando o aluno lê um texto cuidadosamente para aprender um determinado conteúdo, ou seja, alcançar um objetivo cognitivo, estamos diante da estratégia cognitiva. Quando lê rapidamente, testando sua facilidade em aprender o conteúdo, agindo conscientemente, está lançando mão de uma estratégia metacognitiva. Segundo Ribeiro (2003, p. 112), “[...] aprendemos sobre as estratégias cognitivas para fazermos progressos cognitivos e sobre as estratégias metacognitivas para monitorizar o progresso cognitivo".

Uma proposta interessante apresentada por Flavell (1987) é o uso de indicadores cognitivos para monitorar as atividades cognitivas. Entendendo melhor, em um evento cognitivo de leitura, a velocidade com que a leitura é realizada é um indicador cognitivo de compreensão ou não do que se lê.

Os estudos metacognitivos podem ser de extrema importância para os professores das séries iniciais que poderão intervir junto a seus alunos, identificando o problema e oferecendo atividades que possibilitem o desenvolvimento desses conhecimentos necessários à aquisição de leitura proficiente. Segundo Jou e Sperb (2005, p. 179):

O modelo proposto por Flavell (1987) destaca [...] a possível interação entre o desenvolvimento dos processos metacognitivos e os processos de informação elementares, referindo- se à influência das limitaçôes no conteúdo específico sobre a aquisição de algum tipo de metacognição. Isto é, o conhecimento metacognitivo específico de determinado domínio se desenvolveria só depois do sujeito ter suficiente conhecimento sobre esse domínio. E exemplifica, dizendo que um indivíduo náo alfabetizado nunca poderia desenvolver habilidades metacognitivas para a leitura. 
O que ainda se vê como prática docente no Brasil é a superficialidade com que a etapa de conhecimento do domínio específico acontece; em geral, o aluno entra em contato com textos sem uma prévia apresentação e, sem ter suficiente conhecimento sobre o domínio da leitura, já lhe é solicitada a elaboração de um resumo do que leu, por exemplo. Os processos metacognitivos, dessa forma, não se desenvolvem, pois não houve, previamente, apropriação do domínio.

Considerando-se, portanto, todos os elementos da estrutura apresentados por Flavell (1987), acredita-se que o professor, com esse conhecimento, seja capaz de criar uma estratégia pedagógica que, de fato, produza reflexão e permita o alcance da leitura proficiente.

Para Brown (1978), a metacognição está associada tanto ao conhecimento sobre os próprios recursos cognitivos ou estratégias mais apropriadas para a realização de uma tarefa específica (conhecimento do conhecimento) quanto à regulação do conhecimento. A regulação do conhecimento envolve a utilização de mecanismos autorregulatórios durante a realização de uma tarefa. Pode-se citar como exemplos de mecanismos autorregulatórios a planificação, a verificação, a monitorização, a revisão e a avaliação das realizaçóes cognitivas.

Especificamente com relação ao ato de ler, há uma série de atividades de natureza metacognitiva que ocorre, apontadas por Brown (1980 apud KATO, 2007). São elas:

a) Definição de objetivos da leitura;

b) Reconhecimento de informaçóes importantes no texto;

c) Ativação da atenção diante das informações mais relevantes;

d) Monitoramento da leitura para testar a compreensão;

e) Constante revisão do objetivo a ser atingido;

f) Utilização de estratégias que corrijam as falhas na compreensão e

g) Recobramento da atenção quando há dispersão pelo leitor.

Com base nessas informações, é possível analisar o material didático utilizado nas escolas de ensino fundamental do país com relação ao uso de estratégias que possibilitem aos alunos o desenvolvimento de habilidades metacognitivas fundamentais para a compreensão leitora. 


\section{Materiais e métodos}

Antes de passar à explanação do corpus da pesquisa e ao tratamento dispensado aos dados, expóem-se, resumidamente, alguns fundamentos teóricos decorrentes da perspectiva adotada tomados como base para a presente pesquisa:

a) A metacognição exerce influência em áreas fundamentais da aprendizagem escolar, tais como, na comunicação e compreensão oral e escrita e na resolução de problemas, constituindo assim, um elemento chave no processo de aprender a aprender( Flavell, 1987)

b) Acredita-se que o modelo global de monitorização cognitiva desenvolvida por Flavell (1979), que inclui quatro aspectos inter-relacionados: conhecimento metacognitivo, experiências metacognitivas, objetivos e açôes possa colaborar com uma prática docente mais efetiva com relação ao ensino da leitura.

Interessa, portanto, a este artigo apresentar ao professor mediador do processo de aprendizado da leitura uma análise de como os três livros didáticos selecionados propóem as atividades de leitura, levando-o a refletir sobre sua utilização.

Esta pesquisa baseia-se em estudos sobre metacognição, em especial pautando-se em autores como Flavell (1979,1987) e Brown (1978).

O material didático analisado é composto por livros adotados pelas escolas públicas municipais do Rio de Janeiro, pelo PNLD (Programa Nacional do Livro Didático) 2014. Escolhemos três dos mais adotados pela SME/RJ:

1) Oliveira, Oliveira Silva, Silva e Araújo. Tecendo linguagens. São Paulo: IBEP, 2012, 3a ed.

2) Beltrão e Gordilho. Diálogo. São Paulo: FTD, 2009, $1^{\text {a }}$ ed.

3) Cereja e Magalhães. Português Linguagens. São Paulo: Atual Editora, 2009, $5^{\text {a }}$ ed. Reformulada.

Pretende-se observar os textos que compóem os referidos livros didáticos e as atividades de leitura propostas pelos autores, se houver. Nosso objetivo é investigar quais são os tipos de atividades propostas a partir da leitura dos textos e se há alguma atividade preliminar que trabalhe o texto, antes da leitura individual, possibilitando o desenvolvimento de capacidades metacognitivas. 
A hipótese que sustenta esta pesquisa é a de que habilidades cognitivas e metacognitivas necessárias para que se alcance proficiência no ato de leitura não são suficientemente trabalhadas pelos livros didáticos, até mesmo os que se apresentam como uma proposta inovadora e revestidos por uma capa de modernidade.

\section{Análise do material didático}

Oliveira e Silva (2012) apresentam no Manual do Professor sua proposta de prática de leitura que, segundo os autores, tem destaque especial nesta obra, sendo o objetivo principal

“contribuir para o desenvolvimento das diversas habilidades que caracterizam um leitor competente: a) identificar, selecionar e localizar informaçóes precisas presentes no texto; b) relacionar informações; c) inferir, identificando elementos implícitos, que estejam ou não escritos; d) avaliar um texto." (Manual do professor, p. 20)

Os autores informam, ainda, que "são propostas diversas abordagens de leitura, embora predomine o sistema de perguntas e respostas, método muito utilizado pelos educadores" (Manual do Professor, p. 21).

Oliveira e Silva (2012) afirmam utilizar estratégias de leitura variadas conforme o gênero trabalhado e que há procedimentos constantes tais como preparação para a leitura que inclui discussão sobre as expectativas dos alunos com relação ao texto e levantamento de hipóteses, leitura oral compartilhada, leitura silenciosa, interpretação oral e interpretação escrita.

O capítulo I - Desvendando contos - da Unidade I apresenta na seção Prática de leitura dois contos: "O chapéu de Charles Kieffer" e "O vagabundo na esplanada de Manuel da Fonseca”. Na apresentação do texto 2, há uma proposta de preparação para a leitura interessante: pede-se que o aluno percorra o texto, observando, apenas, as palavras em destaque, respondendo, em seguida, de que assunto trata o texto. Este é o único momento, no capítulo I, que se permite uma reflexão, por parte do aluno, sobre palavras que conhece ou não, sendo possível a ativação de frames que o permitam 
inferir sobre o assunto tratado pelo texto. Com esta atividade, trabalha-se metacognitivamente.

Com relação às atividades que seguem os textos - Por dentro do texto - limitam-se a perguntas acerca do tempo e ambiente da narrativa, entendimento vocabular, reconhecimento de tipo textual (narração, descrição e argumentação) e classe gramatical de palavras destacadas no texto.

O capítulo 2 da Unidade I traz o gênero textual romance. Os dois textos usados na seção Prática de Leitura são fragmentos. Antes do texto 1 ser lido, se propóe uma consulta ao glossário para conferir o significado da palavra destacada no primeiro parágrafo. A partir da verificação de que a palavra destacada não está em uso nos dias atuais, se propóem uma reflexão ao aluno sobre o tempo em que se passa a história contada. Há poucas perguntas sobre o texto que dizem respeito, de fato, à compreensão leitora. O texto 2 é um fragmento do mesmo romance, a continuação da história. Este capítulo apresenta três textos fragmentos nas seçôes de Prática de Leitura, sempre seguidas de perguntas que não permitem ao professor aferir se, de fato, seus alunos compreenderam o que foi lido. Há perguntas que, tal como foram elaboradas, permitem uma "busca por respostas" no texto, permitindo a transcrição de trechos.

A Unidade II divide-se em 2 capítulos, sendo trabalhados os gêneros poema e romance. O capítulo I apresenta cinco momentos de prática de leitura. No entanto, persiste o sistema de perguntas e respostas, com o seguinte padrão:

a) Copiar/transcrever trechos do texto.

b) Identificar narrador.

c) Apresentar intenção do narrador.

d) Apresentar o tempo e ambiente em que se passa a história.

e) Identificar tipo textual.

f) $\mathrm{O}$ que significa determinado trecho ou palavra.

g) O que você entende por...

h) Explicar o que autor quis dizer ou por que deu esse título ao texto.

Esse padrão é o mesmo em todos os capítulos.

As Unidades III e IV apresentam dois capítulos com uma média de quatro textos cada. Os gêneros textuais apresentados na Unidade III são artigos de 
opiniāo, crônica, conto e propaganda. Na Unidade IV, trabalha-se com notícias, entrevistas e o gênero textual mangá.

Ainda que os autores afirmem que há diversas propostas de abordagem da leitura, o que se observa é o esquema tradicional de leitura seguida de uma série de perguntas de interpretação textual e outras sobre questóes gramaticais, apropriando-se do momento da leitura para usar o texto como apoio para as aulas de gramática.

O segundo livro selecionado, Diálogos, de Beltrão \& Gordilho (2009), é dividido em sete módulos que apresentam dois ou três textos introduzidos por uma pequena apresentação e imagens variadas (ilustrações, mapas, gráficos, etc).

Em geral, são apresentados textos fragmentados seguidos de uma seção intitulada dialogando com o texto seguindo o padrão perguntas e respostas do tipo:

1) Na sua opinião, por que...

2) $\mathrm{Na}$ oração em destaque, que termo demonstra/informa/...

3) Que marcas linguísticas presentes no texto...

4) Que recurso poético é empregado...

5) Copie em seu caderno a oração que apresenta um predicado verbo -nominal/adjetivo/sujeito paciente

6) O termo minha prima exerce a função de sujeito das oraçóes. Esse termo indica quem sofre ou quem pratica a ação?

Não são apresentadas atividades anteriores ao contato com o texto que possam preparar o aluno para o que vai ler, instigando sua curiosidade ou permitindo reflexóes e inferências.

O terceiro livro analisado - Português Linguagens de Cereja e Magalhães (2009) é dividido em quatro unidades, cada uma contendo três capítulos. Em cada capítulo é trabalhado um único texto, seguido por uma seção intitulada Estudo do texto. Esta seção apresenta uma série de perguntas de compreensão e interpretação do tipo:

1) Em que lugar ocorre...

2) Como você acha que ...

3) Qual é o recurso estilístico usado...

4) Qual é o modo verbal empregado...

5) Dê sua opinião sobre... 
Este livro, como os demais, não oferece atividades preliminares à leitura, permitindo que o aluno se prepare para o texto que vai ler. Além disso, as atividades que buscam aferir se houve compreensão leitora limitam-se a perguntas objetivas que podem ser "buscadas" no texto (com exceção das perguntas que pedem opinião pessoal).

Como se pôde ver, nos três livros analisados, com exceção do primeiro livro que, esporadicamente, faz uso dessa abordagem do texto, não há, antes da leitura propriamente dita, um texto inicial que permita ao aluno criar hipóteses sobre a leitura que fará e que o permita acionar os conhecimentos prévios e de mundo para a compreensão da leitura. Os autores também não lançam mão de textos que agucem a curiosidade do aluno ou que permitam a contextualização, as inferências e a ativação de frames que o auxiliarão na compreensão leitora.

Tomando Brown (1980 apud KATO, 2007) como referência teórica para a análise que se oferece, selecionamos quatro critérios apresentados pelo referido autor para analisar os livros a partir das atividades de natureza metacognitiva, como pode ser visto na tabela I. Os critérios para análise são:

1) Uso de atividades que definam claramente os objetivos da leitura.

2) Uso de estratégias que permitam reconhecimento de informaçóes importantes no texto, tais como destaques especiais a palavras ou tre chos do texto.

3) Uso de atividades de ativação da atenção diante das informaçóes relevantes.

4) Utilização de estratégias que corrijam as falhas na compreensão como atividades que induzam uma volta ao texto para releituras, por exemplo.

$\mathrm{Na}$ análise do primeiro critério, consideramos textos apresentados antes do texto principal que direcionassem a leitura, de forma clara, para um determinado objetivo. Retiramos dos livros analisados exemplos que ilustram a utilização dessa estratégia:

(1) A palavra festa lembra alegria, risos, encontros... Neste conto, porém, a festa é um mistério, os acontecimentos são fora do comum... Será que você gostaria de ser um dos convidados? Leia e confira. (Beltrão \& Gordilho, 2009, p. 67, destaque dos autores) 
(2) Você vai ler uma continuação da história. Verifique se suas hipóteses estavam certas. (Oliveira, Oliveira Silva, Silva e Araújo, 2012, p. 37)

No livro Português Linguagens, antes da leitura de cada fragmento de texto, há uma pequena introdução cujo objetivo é contextualizar toda vez que se apresenta um fragmento do texto. Em algumas dessas introduções, há definição dos objetivos da leitura. Consideramos, nesta análise, somente aquelas atividades ou textos que apresentassem ao leitor os objetivos da leitura de forma bem direta, como "leia o texto a seguir e descubra por que..." ou "Entre no clima de tensão do conto e descubra se há uma explicação para...”

Com relação ao critério 2, levamos em conta destaques especiais nos textos, como pode ser visto no exemplo a seguir:

\section{(1) Antes de ler}

O texto seguinte foi escrito pelo autor português Manuel da Fonseca. Percorra-o observando apenas as palavras em destaque, e responda: qual é o assunto de que ele trata? (Oliveira, Oliveira Silva, Silva e Araújo, 2012, p. 19-20)

O critério 3 foi observado com relação a informaçóes apresentadas que ativam a atenção através do que é relevante para a compreensão leitora. São informaçóes dadas antes ou durante a leitura. Não foram consideradas informaçóes sobre autor do texto ou livro em que foi publicado por considerarmos que tais informaçóes não ativam a atenção do leitor para o conteúdo do que lê:

(1) A charge é uma comunicação composta geralmente de imagens e palavras que revelam um problema social, político. Seu objetivo é a crítica humoristica, ou seja, a denúncia de um problema de forma engraçada, capaz de nos fazer rir e refletir sobre ele. O que a charge critica? (Oliveira, Oliveira Silva, Silva e Araújo, 2012, p. 106)

E, finalmente, com relação ao critério 4 observamos atividades que induzam uma volta ao texto para releituras. Por razóes metodológicas, consideramos as atividades propostas em cada texto, independentemente da quantidade. 
(2) Releia este fragmento do texto: (...)

Esse trecho, extraído do início do texto, é uma pista do que iria ocorrer posteriormente no hospital.

a) Que mudança ocorre com as personagens quanto ao papel que cada um deveria desempenhar no hospital?

b) Identifique, no texto, trechos que justifiquem sua resposta anterior. (Cereja e Magalhães, 2009, p. 51)

Apresentamos, a seguir, tabela que sintetiza a análise feita de acordo com os critérios pré-estabelecidos apresentados:

\begin{tabular}{|l|l|l|l|}
\hline Livros analisados & $\begin{array}{l}\text { Tecendo } \\
\text { linguagens. }\end{array}$ & \multicolumn{1}{|c|}{ Diálogo. } & $\begin{array}{c}\text { Português } \\
\text { Linguagens. }\end{array}$ \\
\hline $\begin{array}{l}\text { Total de textos trabalhados } \\
\text { nas atividades de leitura }\end{array}$ & 32 & 14 & 12 \\
\hline $\begin{array}{l}\text { Estratégias metacognitivas } \\
\text { Utilizadas } \\
\text { Quantidade } \\
\text { Tipo } \downarrow\end{array}$ & $15 / 32(47 \%)$ & $14 / 14(100 \%)$ & $0 / 12$ \\
\hline Critério 1 & $9 / 32(28,9 \%)$ & $0 / 14$ & $0 / 12$ \\
\hline Critério 2 & $6 / 32(19 \%)$ & $9 / 14(65 \%)$ & $2 / 12(17 \%)$ \\
\hline Critério 3 & $6 / 32(19 \%)$ & $3 / 14(22 \%)$ & $4 / 12(34 \%)$ \\
\hline Critério 4 & & & \\
\hline
\end{tabular}

Tabela1: Síntese da análise dos livros didáticos de acordo com os critérios retirados de Brown (1980 apud KATO, 2007).

Como se pode ver na tabela I, o livro Tecendo Linguagens oferece maior quantidade de textos a serem trabalhados nas atividades de leitura, além de propor estratégias metacognitivas que se enquadram nos quatro critérios observados: em $47 \%$ das atividades de leitura há propostas que levam o aluno a destacar os objetivos da leitura, em $28,9 \%$ são propostas atividades que permitem que o aluno reconheça informaçóes importantes no texto, em 19\% das atividades de compreensão leitora há questóes que propiciam ativação da 
atenção diante das informações relevantes para a compreensão textual e em $19 \%$ das questôes propostas são oferecidas estratégias que permitam ao leitor corrigir suas falhas na compreensão do texto.

Ainda que o livro Diálogos não ofereça atividades que permitam que o aluno reconheça informaçóes importantes no texto, trabalha bem as demais estratégias: em todas as atividades de leitura foram encontradas estratégias que se enquadram no critério 1 ; com relação ao critério que dá conta da ativação da atenção para o que importa no texto foram encontrados em $65 \%$ das atividades de compreensão textual. $\mathrm{O}$ critério 4 foi o menos trabalhado mas, ainda assim, foram encontrados em $22 \%$ dos exercícios propostos.

O livro Português linguagens é o menos recomendado se buscarmos um ensino de leitura a partir de estratégias metacognitivas, como se pode ver no quadro I: não encontramos propostas que trabalhem os objetivos da leitura ou que permitem que o aluno reconheça informaçóes importantes no texto; em $17 \%$ dos exercícios encontramos estratégias de ativação da atenção. O critério melhor trabalhado, com $34 \%$ de atividades propostas, foi o critério 4 que busca oferecer estratégias que permitam ao leitor corrigir suas falhas na compreensão do texto. Ainda assim, não consideramos um número significativo.

\section{Considerações finais}

Diante da análise apresentada, pode-se dizer que o presente artigo alcançou o objetivo de promover reflexóes acerca dos processamentos cognitivos e metacognitivos do ato de ler a partir da análise de livros didáticos adotados por escolas do ensino fundamental do município do Rio de Janeiro. Buscamos observar em três livros didáticos incluídos no PNLD de 2014, dos mais adotados, como são apresentadas as atividades de leitura e se os autores lançam mão de atividades que trabalhem as habilidade metacognitivas responsáveis pela proficiência leitora por partirmos da premissa de que o alcance da leitura proficiente se pauta na consciência do indivíduo acerca do seu processo de aprendizagem.

Selecionamos quatro critérios analíticos daqueles apresentados por Brown (1980 apud KATO, 2007) : definição de objetivos da leitura, reconhecimento de informaçóes importantes no texto, ativação da atenção diante das informaçôes mais relevantes e utilização de estratégias que corrijam as falhas 
na compreensão. A partir da análise do material didático com base nesses critérios, corroboramos a hipótese de que habilidades cognitivas e metacognitivas necessárias para que se alcance proficiência no ato de leitura, tais como, atenção, reflexão e inferenciação, por exemplo, não são suficientemente trabalhadas nos livros didáticos analisados.

Esperamos, com esta pesquisa, auxiliar, sobretudo na tarefa de escolha do livro didático pelo professor, bem como provocar uma reflexão sobre a necessidade de se repensar o ensino de leitura tomando por base as pesquisas sobre metacognição.

\section{Referências}

BELTRÃO E GORDILHO. Diálogo. São Paulo: FTD, 1a ed, 2009, p. 304 BROWN, A. L. Knowing when, where, and how to remember: A problem of metacognition. Em R. Glaser (Org.), Advances in instructional psychology (Vol. 1). Hillsdale, N.J.: Erlbaum, 1978, p. 77-165

CEREJA E MAGALHÃES. Português linguagens. São Paulo: Atual Editora, $5^{\mathrm{a}}$ ed. Reformulada, 2009, p. 288.

FLAVELL, J. H. Metacognition and cognition monitoring: a new area of cognitive- developmental inquiry. american psychologist. Outubro, 1979, p. $906-911$

Speculations about the nature and development of metacognition. Em F. E. Weinert \& R. Kluwe (Orgs.), Metacognition, motivation, and understanding. Hillsdale, N. J.: Erlbaum, 1987, p. 1-16

FLAVELL, J. H. \& WELLMAN, H. M. Metamemory. In R. V. Kail, \& O. W. Hagen (Eds.), Perspectives on the development of memory and cognition. Hillsdale, N.Y.: Lawrence Erlbaum Associates, 1977, p. 333.

JOU, Graciela Inchausti \& SPERB, Tania Mara. A metacognição como estratégia reguladora da aprendizagem. Porto Alegre, 2006.

KATO, M. O aprendizado da leitura. 6a ed. São Paulo: Martins Fontes, 2007, p. 121.

KLEIMAN, A. Oficina de leitura: teoria e prática. 13a ed. Campinas: Pontes, 2010, p. 155.

OLIVEIRA, OLIVEIRA SILVA, SILVA E ARAÚJO. Tecendo linguagens. São Paulo: IBEP, $3^{\mathrm{a}}$ ed., 2012, p. 280 
PALOMANES, R. Sobre processamento cognitivo e aquisição de conhecimento. In: PALOMANES, R. \& BRAVIN, A (org) Práticas de Ensino do Português. São Paulo: Contexto, 2012, p. 272

RIBEIRO, Célia. Metacognição: um apoio ao processo de aprendizagem. psicologia: reflexão e crítica, 16 (1), 2003, p. 109-116

\title{
THE METACOGNITIVE PROCESSING IN THE ACT OF READING: RETHINKING EDUCATION.
}

\begin{abstract}
The aim of this paper is to present and discuss proposals around the unconscious and automatic behavior of the player while the activity of reading (cognitive processing) as well as the activities carried out by it in a controlled way (metacognitive processing). Through metacognitive activities, the student makes connections between different knowledge reaching understanding of reading.
\end{abstract}

KEY-WORDS: cognitive processing; metacognitive processing; reading competence

Recebido em: 08/09/2015

Aprovado em: 29/01/2016 